\title{
Classical methods to measure aortic valve area in the era of new invasive therapies: still accurate enough?
}

\author{
Victoria Delgado · Jeroen J. Bax
}

Received: 6 August 2008/Accepted: 21 August 2008/Published online: 18 September 2008

(C) The Author(s) 2008. This article is published with open access at Springerlink.com

Aortic stenosis is the most common native valve disease, with increasing prevalence among the ageing population of the Western countries [1,2]. Aortic valve replacement is the only effective treatment for patients with severe, symptomatic aortic stenosis [3]. However, there are certain groups of patients who are denied surgery because of high risk of operative mortality [4]. Particularly, older age and left ventricular dysfunction have been related to high operative risk and poor outcome after aortic valve replacement $[5,6]$.

In order to provide to these high-risk patients a lessinvasive therapy, but as effective as surgical aortic valve replacement, several transcatheter aortic valve replacement (TAVR) techniques have been developed in the last years [7-13]. Safety and feasibility of different TAVR strategies were evaluated in preclinical studies [7] and, after the first-in-man experience in 2002 [8], different generations of either balloonexpandable or self-expandable valve prosthesis have been investigated in up to 1,000 high-risk patients with severe symptomatic aortic stenosis [9-14]. Currently, two different transcatheter implantation strategies are being used: the retrograde transfemoral approach and

V. Delgado · J. J. Bax $(\bowtie)$

Department of Cardiology, Leiden University Medical Center, Albinusdreef 2, 2333 ZA Leiden, The Netherlands e-mail: j.j.bax@lumc.nl

V. Delgado

e-mail: v.delgado@lumc.nl the transapical approach, proposed in patients with extensive calcification and tortuosity of the iliac arteries. The results are encouraging, with implantation success rate about $90 \%$ in experienced centres, either using a transfemoral or transapical approach [10, 13, 14]. Significant hemodynamic and clinical improvements have been reported for both balloonand self-expandable devices [10, 13, 14]. In addition, mortality rates at 30 -day follow-up range from $5 \%$ to $18 \%$ and 12-month survival rate is about $70-80 \%$, being the majority of the late deaths due to comorbidities [10, 13, 14]. Last, but not least, TAVR has a non-depreciable frequency of complications, the majority of them associated to vascular access (vascular injury 10-15\%) and device positioning and deployment (paravalvular leakage (30-50\%), cardiac tamponade (7\%), arrhythmias (4\%), coronary artery occlusion $(5 \%)$ and prosthetic valve embolization (10\%)) [9-14]. All these procedural-related complications may be circumvented with a careful selection of potential candidates, procedural risk assessment and detailed evaluation of the aortic valve anatomy and vascular access.

According to the first consensus recently reached by the European Association of Cardio-Thoracic Surgery and the European Society of Cardiology representatives, patient selection for TAVR should include confirmation of aortic stenosis severity, clinical evaluation and operative-risk analysis and, assessment of feasibility and exclusion of contraindications for TAVR [15]. 
With regard to aortic stenosis severity assessment, transthoracic 2-dimensional (2D) echocardiography is routinely used for this purpose. Current guidelines define severe aortic stenosis when aortic valve area is less than $1 \mathrm{~cm}^{2}$ [3]. The aortic valve area is usually assessed by the 2D derived continuity equation, although it is subjected to important assumptions that can lead to error [16]. The continuity equation assumes a circular geometry of the left ventricular outflow tract (LVOT) and considers a laminar flow of uniform velocity across the LVOT. Particularly, in elderly patients with severe aortic stenosis, an asymmetrical basal septal hypertrophy ("sigmoid septum") occurs frequently and may result in irregular geometry of the LVOT. In addition, the flow through the LVOT usually is non-laminar due to hyperdynamic function or anatomic obstruction, and consequently flow velocities are not uniform. Finally, the measurement of flow velocity at the LVOT is strongly dependent on the pulsed-wave Doppler sample area position, introducing another error to the aortic valve area calculation [16].

Current 3-dimensional (3D) imaging techniques enable the exact characterization of the LVOT geometry and avoid the geometrical assumptions subjected to $2 \mathrm{D}$ continuity equation $[17,18]$. Previous work by Burgstahler et al. [19], demonstrated, with the use of magnetic resonance imaging, the elliptical shape of the LVOT in patients with and without aortic stenosis. In addition, two studies used 3D echocardiography and confirmed the elliptical geometry of the LVOT in patients with varying degrees of aortic stenosis, being more pronounced in those patients with basal septal hypertrophy [17, 18]. Consequently, the aortic valve area calculated by 3D echocardiography, taking into account the elliptical geometry of the LVOT, agreed better with the anatomical standard used as a reference (aortic valve area calculated by $3 \mathrm{D}$ planimetry), whereas the $2 \mathrm{D}$ continuity equation consistently underestimated the aortic valve area $[17,18]$. This finding has important clinical implications, since patients with aortic stenosis may have different grades of severity depending on the method used to calculate the aortic valve area and, subsequently, the therapeutic management may change.

In addition, the assessment of the feasibility of TAVR comprises the exact sizing of the aortic annulus, the assessment of coronary anatomy and the sizing and characterization of peripheral arteries
[15]. An accurate sizing of the aortic annulus may minimize the risk of paravalvular leakage and prosthesis migration after implantation. Furthermore, since bicuspid anatomy and extensive calcification of the aortic cups have been related to misdeployment of the prosthesis [20], the detailed characterization of the valve anatomy and calcification extent could be crucial in selection of TAVR candidates to ensure the success of the procedure.

Among 3D imaging techniques, multi-slice computed tomography (MSCT) enables a comprehensive evaluation of the aortic valve and its relation with surrounding structures, providing accurate measurement of the aortic annulus diameters, detailed evaluation of the aortic valve anatomy and valve calcifications [21]. Furthermore, the relation between the aortic annulus and the ostium of the left coronary artery can be exactly evaluated with MSCT, and subsequently, potential life-threatening proceduralrelated complications, such as occlusion of the ostium of the left coronary artery by a bulky aortic cusp, can be avoided [12].

In the current issue of the Journal, Doddamani et al. have assessed the LVOT geometry and area using 64-slice MSCT. For this purpose, 30 patients with normal left ventricular volumes and ejection fraction and normal aortic valve anatomy and function were scanned. The LVOT area was calculated considering circular geometry, similarly to 2D echocardiography, or elliptical geometry, measuring the longest and the shortest diameters of the LVOT at the transversal plane. These two LVOT area estimates were compared to the LVOT area obtained by planimetry. The authors observed in the majority of the patients an elliptical geometry of the LVOT rather than circular geometry, as the median LVOT eccentricity index of 0.18 also reflected. Consequently, the LVOT area estimate was consistently smaller when circular geometry was assumed, whereas the LVOT area estimate, when LVOT was considered ellipticalshaped, showed better agreement with the planimetry-derived LVOT area.

This study, along with the aforementioned studies [17-19], indicates the potential errors that can be made in aortic valve area calculation by considering circular geometry of the LVOT. In aortic stenosis patients, the accurate estimate of the aortic valve area is crucial since the therapeutic decision depends not only on the presence of symptoms but also on the 
severity of the aortic stenosis. High-risk patients with severe, symptomatic aortic stenosis are potential candidates for TAVR and the exact characterization of the aortic valve anatomy and geometry becomes extremely important in order to increase the success rate and to reduce the probability of proceduralrelated complications. In this challenging novel therapeutic field, MSCT provides a comprehensive assessment of the aortic valve and may be of great value for the selection of TAVR candidates.

Open Access This article is distributed under the terms of the Creative Commons Attribution Noncommercial License which permits any noncommercial use, distribution, and reproduction in any medium, provided the original author(s) and source are credited.

\section{References}

1. Iung B, Baron G, Butchart EG et al (2003) A prospective survey of patients with valvular heart disease in Europe: the euro heart survey on valvular heart disease. Eur Heart J 24:1231-1243

2. Nkomo VT, Gardin JM, Skelton TN, Gottdiener JS, Scott CG, Enriquez-Sarano M (2006) Burden of valvular heart diseases: a population-based study. Lancet 368:1005-1011

3. Bonow RO, Carabello BA, Kanu C et al (2006) ACC/AHA 2006 guidelines for the management of patients with valvular heart disease: a report of the American College of Cardiology/American Heart Association Task Force on Practice Guidelines (writing committee to revise the 1998 guidelines for the management of patients with valvular heart disease): developed in collaboration with the Society of Cardiovascular Anesthesiologists: endorsed by the Society for Cardiovascular Angiography and Interventions and the Society of Thoracic Surgeons. Circulation 114: e84-e231

4. Iung B, Cachier A, Baron G et al (2005) Decision-making in elderly patients with severe aortic stenosis: why are so many denied surgery? Eur Heart J 26:2714-2720

5. Alexander KP, Anstrom KJ, Muhlbaier LH et al (2000) Outcomes of cardiac surgery in patients $>$ or $=80$ years: results from the National Cardiovascular Network. J Am Coll Cardiol 35:731-738

6. Mihaljevic T, Nowicki ER, Rajeswaran J et al (2008) Survival after valve replacement for aortic stenosis: implications for decision making. $\mathrm{J}$ Thorac Cardiovasc Surg 135:1270-1278

7. Andersen HR, Knudsen LL, Hasenkam JM (1992) Transluminal implantation of artificial heart valves. Description of a new expandable aortic valve and initial results with implantation by catheter technique in closed chest pigs. Eur Heart J 13:704-708

8. Cribier A, Eltchaninoff H, Tron C et al (2004) Early experience with percutaneous transcatheter implantation of heart valve prosthesis for the treatment of end-stage inoperable patients with calcific aortic stenosis. J Am Coll Cardiol 43:698-703

9. Grube E, Laborde JC, Gerckens U et al (2006) Percutaneous implantation of the CoreValve self-expanding valve prosthesis in high-risk patients with aortic valve disease: the Siegburg first-in-man study. Circulation 114:16161624

10. Grube E, Schuler G, Buellesfeld L et al (2007) Percutaneous aortic valve replacement for severe aortic stenosis in high-risk patients using the second-and current third-generation self-expanding CoreValve prosthesis: device success and 30-day clinical outcome. J Am Coll Cardiol 50:69-76

11. Lichtenstein SV, Cheung A, Ye J et al (2006) Transapical transcatheter aortic valve implantation in humans: initial clinical experience. Circulation 114:591-596

12. Webb JG, Chandavimol M, Thompson CR et al (2006) Percutaneous aortic valve implantation retrograde from the femoral artery. Circulation 113:842-850

13. Webb JG, Pasupati S, Humphries K et al (2007) Percutaneous transarterial aortic valve replacement in selected high-risk patients with aortic stenosis. Circulation 116:755-763

14. Descoutures F, Himbert D, Lepage L et al (2008) Contemporary surgical or percutaneous management of severe aortic stenosis in the elderly. Eur Heart J 29:1410-1417

15. Vahanian A, Alfieri O, Al-Attar N et al (2008) Transcatheter valve implantation for patients with aortic stenosis: a position statement from the European Association of Cardio-Thoracic Surgery (EACTS) and the European Society of Cardiology (ESC), in collaboration with the European Association of Percutaneous Cardiovascular Interventions (EAPCI). Eur Heart J 29:1463-1470

16. Flachskampf FA (2008) Severe aortic stenosis with low gradient and apparently preserved left ventricular systolic function-under-recognized or overdiagnosed? Eur Heart J 29:966-968

17. Perez de Isla L, Zamorano J, de la Perez YR et al (2008) Quantification of aortic valve area using three-dimensional echocardiography. Rev Esp Cardiol 61:494-500

18. Poh KK, Levine RA, Solis J et al (2008) Assessing aortic valve area in aortic stenosis by continuity equation: a novel approach using real-time three-dimensional echocardiography. Eur Heart J. doi:10.1093/eurheartj/ehn022

19. Burgstahler C, Kunze M, Loffler C, Gawaz MP, Hombach V, Merkle N (2006) Assessment of left ventricular outflow tract geometry in non-stenotic and stenotic aortic valves by cardiovascular magnetic resonance. J Cardiovasc Magn Reson 8:825-829

20. Zegdi R, Ciobotaru V, Noghin M et al (2008) Is it reasonable to treat all calcified stenotic aortic valves with a valved stent? Results from a human anatomic study in adults. J Am Coll Cardiol 51:579-584

21. Tops LF, Wood DA, Delgado V et al (2008) Noninvasive evaluation of the aortic root with multislice computed tomography: implications for transcatheter aortic valve replacement. J Am Coll Cardiol Image 1:321-330 